Research Article

\title{
Structural Analysis of Polyhedral Oligomeric Silsesquioxane Coated SiC Nanoparticles and Their Applications in Thermoset Polymers
}

\author{
Md. Reza-E-Rabby, Shaik Jeelani, and Vijaya K. Rangari \\ Department of Materials Science and Engineering, Tuskegee University, Tuskegee, AL 36088, USA \\ Correspondence should be addressed to Vijaya K. Rangari; rangariv@mytu.tuskegee.edu
}

Received 18 August 2015; Accepted 8 November 2015

Academic Editor: Stefano Bellucci

Copyright (C) 2015 Md. Reza-E-Rabby et al. This is an open access article distributed under the Creative Commons Attribution License, which permits unrestricted use, distribution, and reproduction in any medium, provided the original work is properly cited.

\begin{abstract}
The SiC nanoparticles (NPs) were sonochemically coated with OctaIsobutyl (OI) polyhedral oligomeric silsesquioxane (POSS) to create a compatible interface between particle and thermoset polymer. X-ray photoelectron spectroscopy (XPS), Fourier transform infrared spectroscopy (FTIR), and X-ray diffraction (XRD) techniques were used to analyze the structure of OI-POSS coated SiC nanoparticles. These results revealed the formation of a covalent bonding between SiC and OI-POSS. The transmission electron microscopy (TEM) analysis of OI-POSS coated SiC nanoparticles has also shown the indication of attachment between these two nanoparticles. The OI-POSS coated SiC nanoparticles were further reinforced into a thermoset resin system in order to evaluate mechanical and thermal properties of nanocomposites. The flexural strength, modulus, and glass transition temperature were found to be enhanced while $\mathrm{SiC}$ and OI-POSS coated $\mathrm{SiC}$ were infused into epoxy system compared to those properties of neat epoxy resin.
\end{abstract}

\section{Introduction}

Silicon carbide $(\mathrm{SiC})$ nanoparticles are extensively used as nanofillers because of their inherent characteristics such as high heat resistance, oxidation resistance, chemical stability, radiation resistance, and wear resistance [1-5]. Recent studies have shown that the addition of $\mathrm{SiC}$ particles in polymeric materials enhances their mechanical and thermal properties [2-5]. The compatibility of $\mathrm{SiC}$ particles in polymer is a critical issue in the fabrication of SiC filler polymer nanocomposites. The other challenges included in this fabrication are the dispersion stability and interfacial adhesion which essentially lead to the formation of a strong bridging network with chemical bonding and homogeneity. The interaction between particles and polymeric interfaces is required to be at an optimum level where cross-linking of the polymers is enhanced without agglomeration of nanoparticles. The literature survey reveals that surface of $\mathrm{SiC}$ has a tendency to oxidize when exposed to air with the formation of $\mathrm{SiO}_{2}$ [6-10]. Surface modification of nanoparticles can play an important role for potential application of nanocomposites. Over the years, researchers have been studying the surface of $\mathrm{SiC}$ for their compatibility in organic, metal, or aqueous media [10-14]. Recently micron size $\mathrm{SiC}$ particles were modified with $\mathrm{Al}^{3+}$ by polyelectrolyte to control the charge level of nanoparticles surfaces [14]. Another study reported the formation of radical group using plasma treatment induced by radio frequency and grafted polymethyl methacrylate (PMMA) onto the $\mathrm{SiC}$ nanoparticles [12]. The above modification of $\mathrm{SiC}$ was performed in order to disperse nanoparticles homogeneously into the aqueous solution. Che and his coworkers [11] coated $\mathrm{SiC}$ surface with the interlayer of $\mathrm{Al}(\mathrm{OH})_{3}$ by heterogeneous nucleation followed by polyacetals layer onto $\mathrm{Al}(\mathrm{OH})_{3}$ and observed enhanced dispersion and suspension stability in butanone without any agglomeration or adhesion between particles [11]. Iijima and Kamiya [13] modified the surface of $\mathrm{SiC}$ nanoparticles by azo radical initiator by reacting successfully unsaturated hydrocarbon (present on $\mathrm{SiC}$ as impurities) with the radical species produced from azo initiator. An excellent dispersion stability in aqueous media was also reported in their study [13]. 
Polyhedral oligomeric silsesquioxane (POSS) is an organic-inorganic hybrid nanomaterial of $0.5-3.0 \mathrm{~nm}$ in dimension. POSS material is widely used for biomedical and nanocomposites applications such as coating materials or surface modifiers, catalysts, and membrane materials. Improved thermal and mechanical properties of thermoset and thermoplastic polymer were reported by grafting, blending, homopolymerization, or copolymerization of POSS [15-28]. Recent studies have also shown the ability of POSS to modify the surface of nanophase of graphene oxide [29], palladium nanoclusters-poly(L-lactic acid) (PLLA) [30], multiwalled carbon nanotube [31], and titanium dioxide [32] and eventually improve dispersion, compatibility, reactivity, and solubility of those tailored nanoparticles into polymer matrix by establishing covalent bond in the POSS and nanoparticle interfaces. The endeavor has also taken researchers to modify surface of carbon fibers $[14,33]$ and poly-p-phenylene benzobisthiazole (PBO) fibers [34] with the compatible functional group such as POSS products to enhance the interlaminar shear strength of the nanocomposites by increasing interfacial adhesion between fibers and epoxy resin matrix in which POSS materials are grafted onto the fibers. Studies have also revealed that hybrid coating of polyurethanes copolymerization with POSS offers higher thermal stability and corrosion resistance while being coated onto aluminum alloys $[35,36]$ by chemically boding into polymer chain. In a nutshell, it was revealed from open literature that POSS products have been evolved as an effective cross-linker that remarkably improves solvent resistivity, thermal stability, and electromechanical-chemical properties of the polymeric nanocomposites.

In this present work, $\mathrm{SiC}$ nanoparticles were coated with OctaIsobutyl (OI) POSS using the novel sonochemical synthesis technique to optimize the characteristics of $\mathrm{SiC}$ as a nanofiller by functionalizing the surface of $\mathrm{SiC}$ with POSS, which can act as a bridging chain between the interface of $\mathrm{SiC}$ and polymeric media for manufacturing the nanocomposites. It was expected that coating of OI-POSS onto $\mathrm{SiC}$ makes nanofillers more compatible into organic media because of the presence of organic outer layers of OI-POSS in its molecular structure. The chemical structure of the neat system and coated $\mathrm{SiC}$ was characterized by X-ray photoelectron spectroscope (XPS), X-ray diffraction (XRD), transmission electron microscope (TEM), and Fourier transform infrared spectroscope (FTIR) with the aim to investigate the surface chemical composition, crystal structure, and morphology of the NPs before and after sonochemical reaction as well as for the physical mixture of the SiC and POSS. Finally, these POSS coated $\mathrm{SiC}$ were incorporated into a thermoset polymer to investigate the thermal and mechanical properties of these coated nanofillers into polymer matrix using differential scanning calorimetry (DSC), thermogravimetric analysis (TGA), and flexural tests. Morphology of the fracture surface from flexural test was also investigated using scanning electron microscope (SEM).

\section{Experimental Procedures}

2.1. Materials. Spherical shape silicon carbide (SiC) nanoparticles (average particle diameter is $\sim 15-30 \mathrm{~nm}$ ) were purchased from MTI Corporation, USA. The OI-POSS (product number MS0825) is procured from Hybrid Plastics, USA. The density, molecular weight, and refractive index of OI-POSS are $1.13 \mathrm{~g} / \mathrm{cm}^{3}, 873.60 \mathrm{FW}$, and 1.47 , respectively. White power OI-POSS is soluble in tetrahydrofuran (THF), n-hexane, and chloroform. The polymer matrix system in this study is a commercially available, low viscosity, two-part system SC780 epoxy resin and purchased from Applied Poleramic Inc. (API), USA. This SC-780 is a toughened epoxy resin system and specifically developed for vacuum assisted resin transfer molding (VARTM) process. The recommended temperature for infusion is $23-27^{\circ} \mathrm{C}$. The resin curing is performed at $25^{\circ} \mathrm{C}$ overnight and subsequently postcured at $71^{\circ} \mathrm{C}-77^{\circ} \mathrm{C}$ for six hours to achieve maximum mechanical and thermal properties as suggested by the manufacture's materials data sheet.

\subsection{Coating of Nanoparticles and Preparation of Nanocomposites}

2.2.1. Sonochemical Synthesis of OI-POSS Coated SiC. The coating of OI-POSS on $\mathrm{SiC}$ nanoparticles was carried out using a sonochemical synthesis technique with a Sonic Vibra Cell probe at amplitude of 55\%. A thermostated liquid circulated stainless steel reaction vessel was used for all the sonochemical reactions. The precalculated amount of OI-POSS $(500 \mathrm{mg}$ for $\mathrm{SiC}:$ POSS $=1: 1$ or $1000 \mathrm{mg}$ for $\mathrm{SiC}:$ POSS $=$ $1: 2$ ) was dissolved into $60 \mathrm{~mL}$-hexane with magnetic stirring at room temperature for 20 minutes. The solution was then mixed with $\mathrm{SiC}$ nanoparticle $(500 \mathrm{mg})$ in a reaction vessel and irradiated with ultrasonic probe under argon gas flow throughout the reaction process. The sonication was carried out for 3 hours in an inert (argon gas) atmosphere at a temperature of $5^{\circ} \mathrm{C}$. After three hours of reaction the product was dried at $60^{\circ} \mathrm{C}$ for 24 hours in an oven. The final product was ground using mortar and pestle to obtain uniform fine free falling powder for further characterization and polymer filler applications.

2.2.2. Physical Mixing of SiC and OI-POSS. In order to compare the sonochemical effect of OI-POSS and SiC the physical mixture of OI-POSS and $\mathrm{SiC}$ was studied by dissolving OIPOSS in $n$-hexane following the same experimental conditions as described in Section 2.2.1 except that magnetic stirrer is used instead of ultrasonic probe irradiation.

2.2.3. Manufacturing Nanocomposites. The precalculated amount of nanoparticles ( $\mathrm{SiC}$ or OI-POSS coated $\mathrm{SiC}$ ) and part A of epoxy SC-780 were weighed carefully and mixed together in a $400 \mathrm{~mL}$ plastic beaker. Sonochemical mixing was carried out using a Sonic Vibra Cell with Ti horn for 60 minutes in a pulse mode of 20 second on and 10 second off at amplitude of 35\%. The beaker containing epoxy part $\mathrm{A}$ and $\mathrm{SiC}$ was partially submerged in a thermostat liquid 
circulating at a constant temperature of $0^{\circ} \mathrm{C}$ to control the heat generated by ultrasonic irradiation. The amplitude and pulse rate of ultrasonic irradiation were adjusted after several trial experiments. It is noticed that sonochemical mixing produced a large number of bubbles in the modified part A of epoxy resin that contain nanofillers. These air bubbles were removed using a vacuum desiccator for one hour. The part $B$ of the epoxy resin (an amine base hardener) was added to the nanomodified part A of SC-780 epoxy resin. This combination of part A with nanofiller and part B is further mixed using THINKY hybrid deforming mixer ARE-250, a noncontact homogenous mixer for $15 \mathrm{~min}$. In this technique, the material container is set at 45-degree angle inside the mixer. The container revolves and rotates at high acceleration with the speed of $2000 \mathrm{rpm}$. These dual centrifugal forces were given to the container which keep pressing materials to outward and down along with the slope of the inner wall of the container and accomplish powerful mixing and deaerating simultaneously. The mixture of nanoparticles and epoxy is then transferred to a stainless steel flexure and compression molds (according to ASTM standards). The specimens in the mold were cured at $25^{\circ} \mathrm{C}$ for 12 hours in an oven. After that the samples were postcured at $75^{\circ} \mathrm{C}$ for 6 hours to complete the curing cycle.

\subsection{Characterization of Nanoparticles and Nanocomposites}

2.3.1. X-Ray Diffraction (XRD). X-ray diffraction (XRD) analyses were carried out using Rigaku D/MAX 2200 Xray diffractometer with $\mathrm{Cu} \mathrm{K} \alpha$ radiation. The diffraction data are collected from $5^{\circ}$ to $80^{\circ}$ of $2 \theta$. The step size and scan rates were $0.2^{\circ}$ and $2^{\circ}$ per min, respectively. The XRD samples were prepared by spreading $\sim 50 \mathrm{mg}$ of nanoparticles on quartz sample holder designed for powders. These XRD experiments were carried out for as-received, neat, and synthesized nanoparticles for comparison.

2.3.2. X-Ray Photoelectron Spectroscopy (XPS). X-ray photoelectron spectroscopy (XPS) is a surface analysis technique to investigate the chemical composition of the surface for a depth of about $2-10 \mathrm{~nm}$ range where X-ray creates photoemission electrons from samples in vacuum in which each element creates an XPS signature. The XPS peaks are proportional to the relative concentrations of the atoms. These atomic percentages were determined from the elemental survey scans. The binding energy of silicon, carbon, and oxygen was reported for each specimen. Approximately $2 \mathrm{mg}$ of each synthesized nanoparticle including as-received $\mathrm{SiC}$ and OI-POSS was pressed onto small square doublesided carbon tape which was attached on the substrate of sample holder of SSX-100 ESCA Spectrometer. XPS survey spectra were obtained with the passing of monochromatic $\mathrm{Al} \mathrm{K} \alpha \mathrm{X}$-ray at $1486.6 \mathrm{eV}$ and photoelectrons were collected at an angle of 55 degrees from the surface normal with $180^{\circ}$ hemispherical analyzer. This high resolution scan was performed for 30 minutes on each specimen under an operating pressure of $2 \times 10^{-9}$ Torr. CasaXPS software was employed for postprocessing of the data.
2.3.3. Fourier Transform Infrared Spectroscopy (FTIR). The measurements of FT-IR spectra were conducted using a Thermo Nicolet FT-IR spectrophotometer (Nexus 470, made in USA). For all synthesized nanoparticles along with asreceived $\mathrm{SiC}$ and OI-POSS, 32 scans at a resolution of $1 \mathrm{~cm}^{-1}$ were used to record the spectra. Approximately $2 \mathrm{mg}$ of powder nanoparticles was placed on the crystal surface in the Smart Performer Accessory and the pressure is applied to the sample by turning the thumbscrew clockwise and spectra were collected and data were saved using the graphical user interface: OMNIC. However before collecting spectra for the specimens, stable background readings were collected when no major change in peak was observed to make sure that instrument is fully purged.

2.3.4. Transmission Electron Microscope (TEM). The transmission electron microscope (TEM) analyses have been carried out for $\mathrm{SiC}$ and OI-POSS coated SiC using a JOEL JEM2010 at $200 \mathrm{kV}$ with Oxford EDS detector for elemental analyses. The TEM specimens were prepared by placing a drop of nanoparticles dispersed into ethanol solution on a copper grid followed by air drying.

2.3.5. Differential Scanning Calorimetry (DSC). Differential scanning calorimetry (DSC) experiments were carried out in the nitrogen atmosphere using a METTLER DSC822 $2^{\mathrm{e}}$ supplied by METTLER Toledo. All the specimens were prepared according to ASTM Standard E1356-03. The temperature was ramped from $25^{\circ} \mathrm{C}$ to $180^{\circ} \mathrm{C}$ at a heating rate of $5^{\circ} \mathrm{C}$ per minute. About $15 \mathrm{mg}$ of sample in an aluminium pan was used for the analysis.

2.3.6. Thermogravimetric Analysis (TGA). TGA analyses were carried out to study the decomposition temperature of polymer, nanoparticle filler content, and other impurities using a METTLER TGA/STDADSC $851^{\mathrm{e}}$. In this technique, changes in the weight of the samples were measured as a function of temperature. The specimens were cut in small pieces of $\sim 10-20 \mathrm{mg}$ and placed in ceramic pan. These samples were heated from $30^{\circ} \mathrm{C}$ to $800^{\circ} \mathrm{C}$ at a heating rate of $10^{\circ} \mathrm{C}$ per minute in a nitrogen atmosphere. The characteristic weight loss curves were generated by the Mettler data acquisition system for all the specimens. All these experiments were carried according to the ASTM Standard E1131-03.

2.3.7. Flexural Tests. The flexural property of both neat SC780 epoxy resin and nanofiller infused resin system was evaluated using Zwick Roell instrument equipped with a TestXpert data acquisition system in three-point bend configuration. The tests were performed according to flexure ASTM D 790-03 standard. The width and thickness of rectangular beam were approximately $12.5 \mathrm{~mm}$ and $4.5 \mathrm{~mm}$, respectively. The beam span length was $70 \mathrm{~mm}$ and a crosshead speed of $2 \mathrm{~mm} / \mathrm{min}$ was used. The support span-to-depth ratio $(L / d)$ was 16 to 1 according to ASTM standard. A minimum of five specimens were tested for each category of the samples. This method was used to determine the flexural strength and modulus of elasticity of epoxy nanocomposites. The maximum 
TABLE 1: Peak search values for SiC and OI POSS coated SiC for XRD analysis.

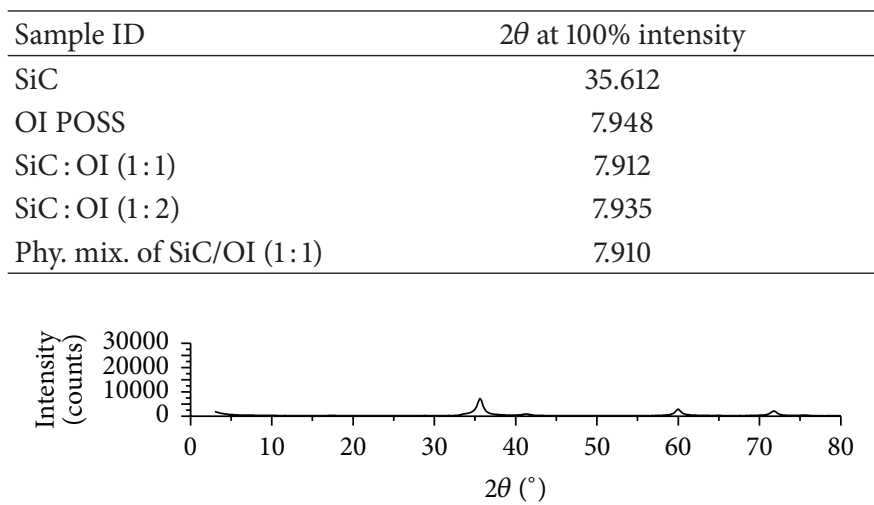

(a) Neat $\mathrm{SiC}$

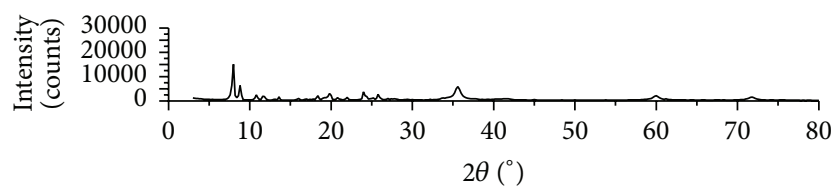

(c) $\mathrm{SiC}: \mathrm{OI}=1: 1$

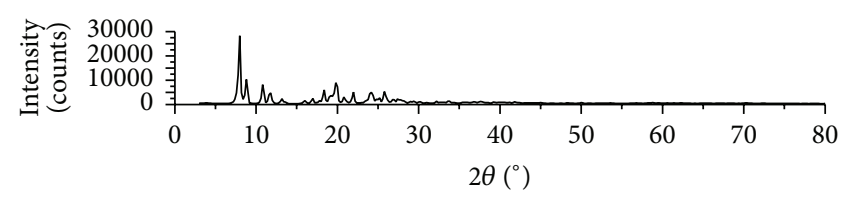

(b) POSS OI neat

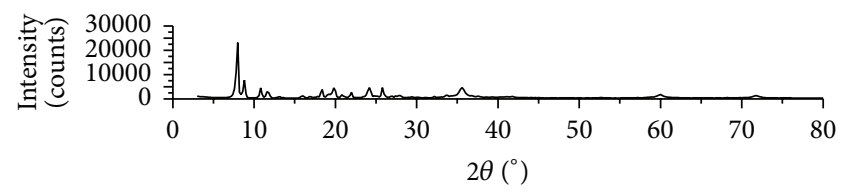

(d) $\mathrm{SiC}: \mathrm{OI}=1: 2$

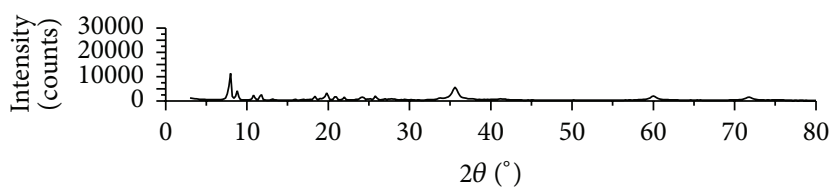

(e) Physical mixture of $\mathrm{SiC}$ : POSS OI $=1: 1$

FIGURE 1: XRD pattern of (a) SiC, (b) OI-POSS, (c) OI-POSS coated SiC (1:1), (d) OI-POSS coated SiC (1:2), and (e) physical mixture of OI-POSS and $\mathrm{SiC}(1: 1)$.

stress at failure on the tension side of a flexural specimen is considered the flexural strength of the material and modulus was calculated from the slope of the stress-strain curves.

2.3.8. Scanning Electron Microscopy (SEM). The fracture surface of the flexure test samples was carried out using JEOL JSM 5800 scanning electron microscope (SEM). The fractured samples were sputter-coated with a very thin conductive layer of gold/palladium to prevent charge build-up by the electron absorbed by the specimen. A 5 to 20 kilovolt accelerating voltage was applied to achieve desired resolution.

\section{Results and Discussions}

\subsection{Characterization of OI-POSS Coated SiC Nanoparticles}

3.1.1. XRD Characterization. Figure 1 shows the XRD spectrum of (a) as-received SiC, (b) OI-POSS, (c) OI-POSS coated $\mathrm{SiC}(1: 1)$, (d) OI-POSS coated $\mathrm{SiC}(1: 2)$, and (e) physical mixture of OI-POSS and $\mathrm{SiC}(1: 1)$. These XRD patterns clearly suggest that all the particles including OI-POSS are crystalline. The XRD peaks of as-received $\mathrm{SiC}$ nanoparticles match exactly JCPDS number 29-1129 indicating that there are no other impurities present in as-received $\mathrm{SiC}$ nanoparticles (Figure 1(a)). From Figures 1(c), 1(d), and 1(e) it was revealed that both OI-POSS and $\mathrm{SiC}$ are present in the coated nanoparticles. It is also noteworthy to mention here that the relative intensities of $\mathrm{SiC}$ decreased because of the presence of OI-POSS coating (Figures 1(c), 1(d), and 1(e)). The peak intensities, FWHM, and $d$-spacing values are summarized in Table 1 as obtained using JADE 6.0 software form XRD spectra.

Interestingly, a decrease in FWHM value for $\mathrm{SiC}$ coated with OI-POSS at $1: 1$ ratio at $35.6^{\circ}$ was observed, with respect to the other mixing ratio and condition. This distinct narrowing of FWHM suggests the increment in particle size according to Debye Scherrer's inverse relationship between particle size and FWHM (the particle size increases with decreasing FWHM for spherical particle shape). The decrease in intensity and FWHM of $\mathrm{SiC}$ peak for the OI-POSS coated $\mathrm{SiC}$ also indicates the coating of OI-POSS on SiC. No appreciable change was observed for physical mixture and of $\mathrm{SiC}$ and OI-POSS at 1:1 mixing ratio.

3.1.2. XPS Characterization. The XPS characterization was explicitly performed in order to confirm the existence of a covalent bond between the OI-POSS and $\mathrm{SiC}$ nanoparticles. Figure 2 depicts the XPS spectra of SiC and OI-POSS coated $\mathrm{SiC}$ composite at different ratios and conditions. For evaluation of the chemical state on the surface of the nanoparticles, detailed spectra of $\mathrm{Si} 2 \mathrm{p}, \mathrm{C}$ 1s, and $\mathrm{O}$ 1s were recorded and analyzed using the CasaXPS software for XPS analysis. 
TABLE 2: Surface chemical composition of OI system form XPS analysis.

\begin{tabular}{|c|c|c|c|c|}
\hline \multirow{2}{*}{ Samples } & \multicolumn{3}{|c|}{ Composition (atomic \%) } & \multirow{2}{*}{ Atomic ratio of $\mathrm{O} / \mathrm{Si}$} \\
\hline & $\mathrm{Si}$ & $\mathrm{O}$ & $\mathrm{C}$ & \\
\hline As-received $\mathrm{SiC}$ & 19.05 & 15.86 & 65.09 & 0.83 \\
\hline POSS OI neat & 16.01 & 24.21 & 59.78 & 1.51 \\
\hline $\mathrm{SiC}: \mathrm{OI}=1: 1$ & 27.64 & 14.74 & 57.62 & 0.53 \\
\hline $\mathrm{SiC}: \mathrm{OI}=1: 2$ & 26.90 & 15.11 & 57.98 & 0.56 \\
\hline Physical mixture of SiC/OI $(1: 1)$ & 39.16 & 12.31 & 48.53 & 0.31 \\
\hline
\end{tabular}

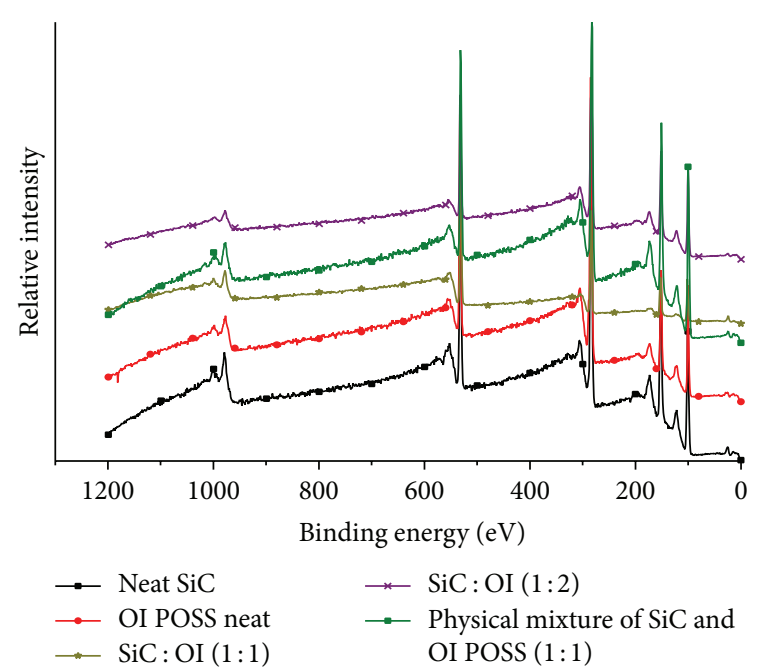

Figure 2: XPS spectra of SiC and OI-POSS coated SiC at different mixing ratios.

The model of peak fitting for CasaXPS was set from a group of Gaussian/Lorentzian line shapes. The experimental data were fitted as a series of splits of Si $2 p$ and $C 1 s$. The estimation of near surface atomic percentage or compositions of the samples was also calculated from the peak areas in the survey spectra using the same software. The XPS spectra of as-received $\mathrm{SiC}$ nanoparticles shown in Figure 2 clearly revealed the strong peak of $\mathrm{O}$ 1s which indicates the presence of oxygen on the SiC nanoparticles. This might attribute to the absorption of atmospheric oxygen and these results are consistent with results from other investigations [7, 8, 37]. Figures 3(a)-3(c) depict the XPS spectra for peaks Si 2p, C $1 \mathrm{~s}$, and O 1s of neat SiC, neat OI-POSS, and OI-POSS coated $\mathrm{SiC}$ at different mixing ratio and conditions.

Sonochemical mixing of $1: 1$ ratio of OI-POSS coated $\mathrm{SiC}$ composite had shown noticeable chemical peak shifts. This indicates the coating of OI-POSS on SiC nanoparticles at 1:1 optimum mixing ratio. These were further confirmed from the elemental concentration at the surface as well as deconvoluted XPS spectrum. The surface chemical composition of OI-POSS and OI-POSS coated $\mathrm{SiC}$ nanoparticles results is summarized in Table 2. The atomic percentage of oxygen in the OI-POSS coated $\mathrm{SiC}$ was expected in between $\mathrm{SiC}$ and OI-POSS system. This criterion was set for the evidences of covalent $\mathrm{Si}-\mathrm{O}-\mathrm{Si}$ or $\mathrm{Si}-\mathrm{O}-\mathrm{C}$ bonding in the coated system. From the atomic percentage, it has also been distinguished between sonochemically coated $\mathrm{SiC}$ with OI-POSS and the physical mixture.

The deconvoluted XPS spectrum of OI-POSS coated SiC at $1: 1$ was shown in Figure 4 . Three fitted peaks for $\mathrm{Si} 2 \mathrm{p}$ and two fitted for $\mathrm{C}$ 1s were observed. As stated previously, the central peak at binding energy (BE) of $100.18 \mathrm{eV}$ (Figure 4(a)) corresponds to the peak of $\mathrm{SiC}$. The other peak at $\mathrm{BE}$ $102 \mathrm{eV}$ is corresponding to the binding energy of silicon oxycarbide as described in the literature [7]. This deviation in measured peaks $(0.9 \mathrm{eV}$ from Figure $4(\mathrm{a}))$ clearly suggest the formation of covalent bonding between $\mathrm{SiC}$ and OIPOSS in the formation of silicon oxycarbide. Interestingly, the peak at $\mathrm{BE} 98.3 \mathrm{eV}$ of $\mathrm{Si}-\mathrm{Si}$ demonstrates the partial coating of OI-POSS on SiC. Moreover, this suggests presence of $\mathrm{Si}$ atoms on $\mathrm{SiC}$. These were confirmed from the surface chemical composition analysis of OI-POSS coated SiC $(1: 1)$ (Si : $\mathrm{C}: \mathrm{O}=27.64: 57.62: 14.74)$ as compared with the chemical composition of OI-POSS ( $\mathrm{Si}: \mathrm{C}: \mathrm{O}=16.01: 59.78: 24.21$ ). For OI-POSS coated $\mathrm{SiC}(1: 2)$, the deconvoluted peak values are close to that of OI-POSS, whereas, from the surface chemical composition analysis, it was observed that the ratio of $\mathrm{Si} / \mathrm{C} / \mathrm{O}$ was the same as that of OI-POSS coated $\mathrm{SiC}$ at a ratio of $1: 1$. This clearly indicates that the optimum ratio of $\mathrm{SiC}$ coated with OI-POSS is $\sim 1: 1$. Interestingly the $\mathrm{O} / \mathrm{Si}$ ratio at surface for both ratios was found to be 0.53 (shown in Table 2). For the physical mixture of $\mathrm{SiC}$ and OI-POSS, this has similar peak as that of sonochemical mixture, except for $\mathrm{O}$ 1s peak. BE of $\mathrm{O}$ 1s peak was observed at $531.26 \mathrm{eV}$, which was previously explained in the literature [38], presumably from the bridge of $\mathrm{Si}-\mathrm{O}-\mathrm{Si}$ or $\mathrm{C}-\mathrm{O}-\mathrm{C}$ or insertion of $\mathrm{O}$ atom into the backbone of $\mathrm{Si}(\mathrm{Si}-\mathrm{O}-\mathrm{C})$. However, at this point the difference between the sonochemical mixture and the direct physical mixture is in surface chemical composition. The atomic percentage of the later has a significant increment in $\mathrm{Si}$ (39.2\%) compared to any other combination indicating previously mentioned bridge formed on the substrate of Si instead of SiC.

3.1.3. FT-IR Characterization. FT-IR spectra of neat $\mathrm{SiC}$ nanoparticles, neat OI-POSS, and OI-POSS coated SiC are shown in Figure 5. These results suggest that the FTIR peaks around $1100 \mathrm{~cm}^{-1}$ and $2910 \mathrm{~cm}^{-1}$ wavelength are due to the asymmetric Si-O-C stretching and C-H antisymmetric and symmetric stretching, respectively $[12,39,40]$. These results are consistent with literature and also confirm the presence of the OI-POSS with SiC nanoparticles in sonochemical and physical mixture methods. 


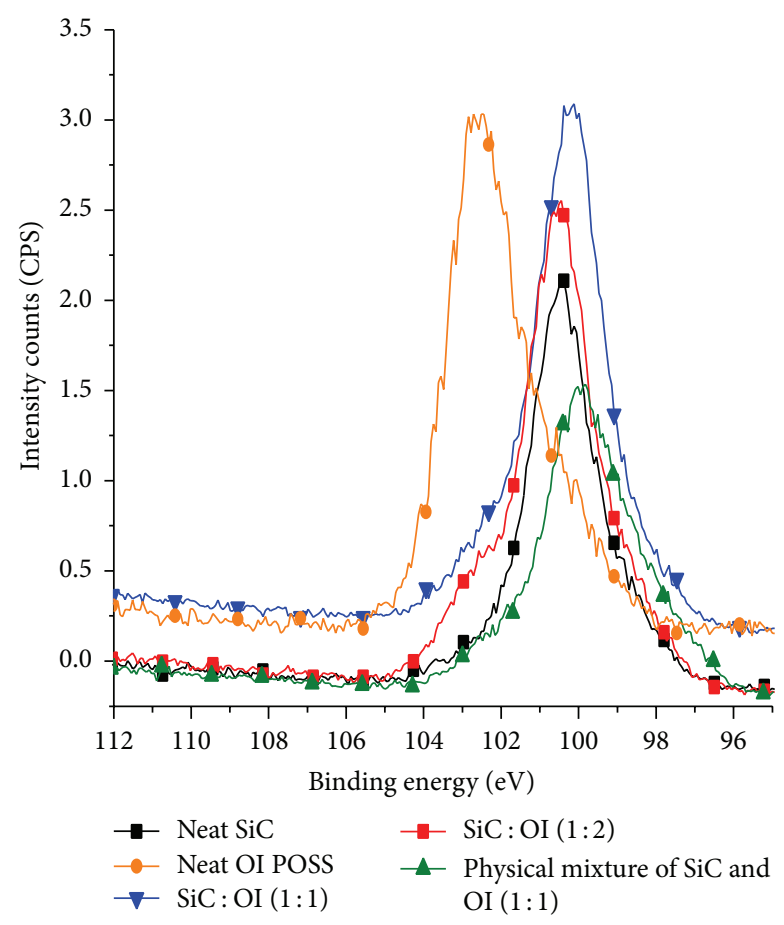

(a)

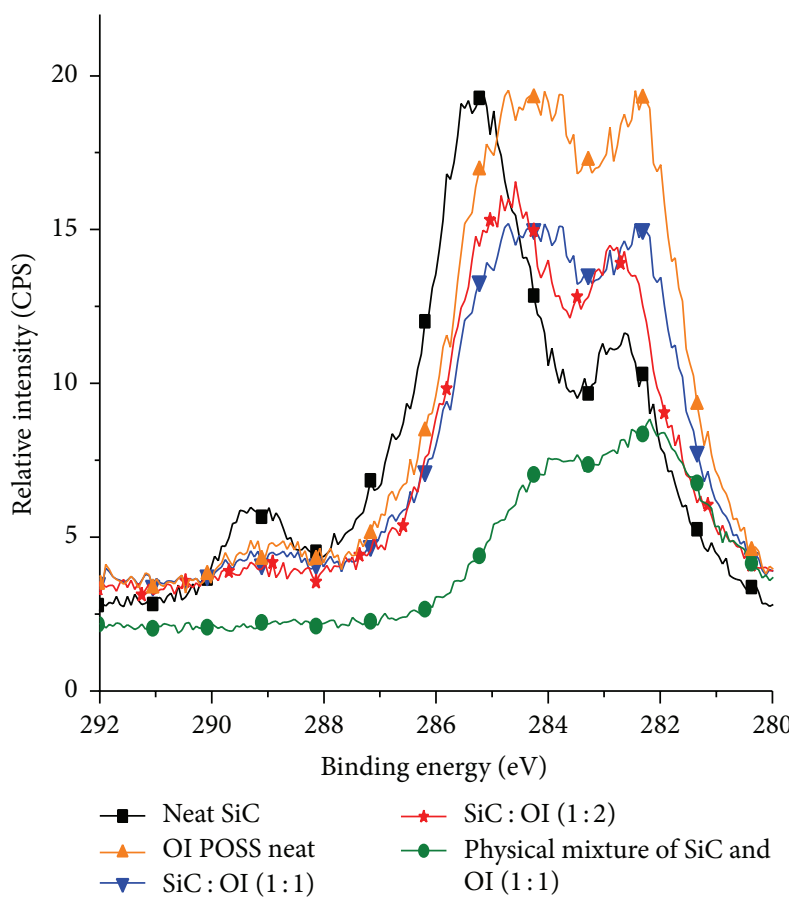

(b)

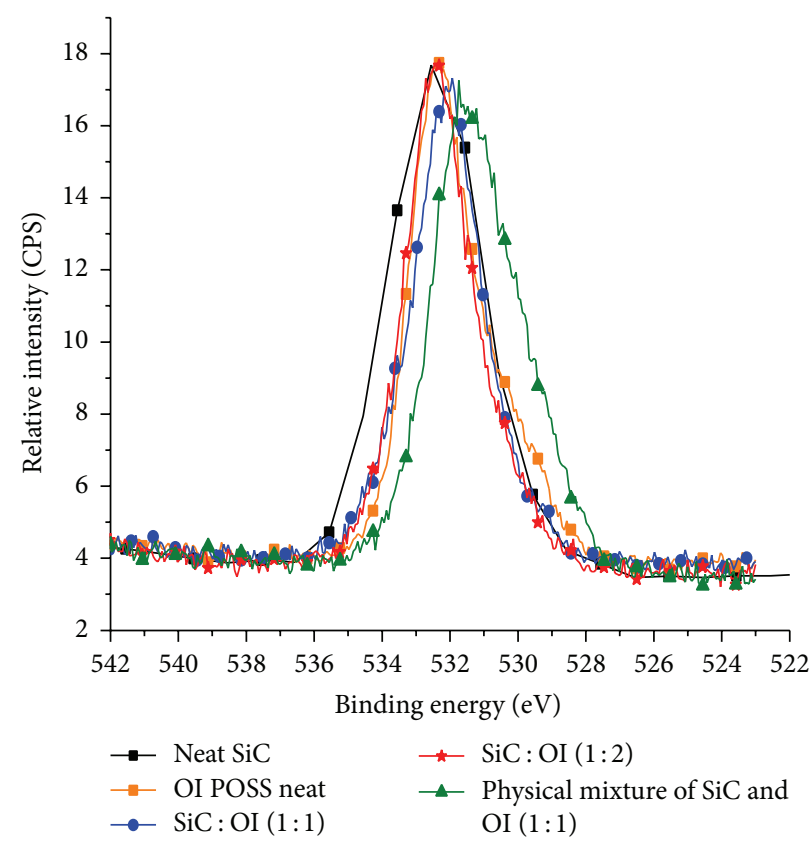

(c)

Figure 3: XPS overlay of (a) Si 2p, (b) C 1s, and (c) O 1s for SiC and POSS OI system.

The FTIR spectra of sonochemically coated SiC/OI-POSS (1:1), SiC/OI-POSS $(1: 2)$, and physical mixture of SiC/OI $(1: 1)$ are also shown in Figure 5. These spectra clearly suggest that the sonochemically coated SiC/OI $(1: 1)$ has broadened peak at wave number $1097 \mathrm{~cm}^{-1}$ that was shifted from $1091 \mathrm{~cm}^{-1}$ of OI-POSS coated $\mathrm{SiC}$ (physical mixture at $1: 1$ ratio). These results imply the covalent bonding between $\mathrm{SiC}$ and OI-POSS with the overlap of Si-O stretching, $\mathrm{Si}-\mathrm{O}-\mathrm{Si}$, and Si-O deformation vibration [41]. Moreover, another peak observed at wave number $2902 \mathrm{~cm}^{-1}$ for physical mixture of $\mathrm{SiC} / \mathrm{OI}-\mathrm{POSS}$ which might be associated with the solvent $\mathrm{n}$-hexane also indicated the existence of $\mathrm{C}-\mathrm{H}_{n}$ bonding in such mixture. A reduced intensity of peak around wave number of $2902 \mathrm{~cm}^{-1}$ for sonochemical coated $\mathrm{SiC} / \mathrm{OI}$-POSS (1:2 ratio) also suggested the tracing of $\mathrm{C}-\mathrm{H}_{n}$ bonding. However, for sonochemically coated $\mathrm{SiC}$ with OI-POSS at 1:1 


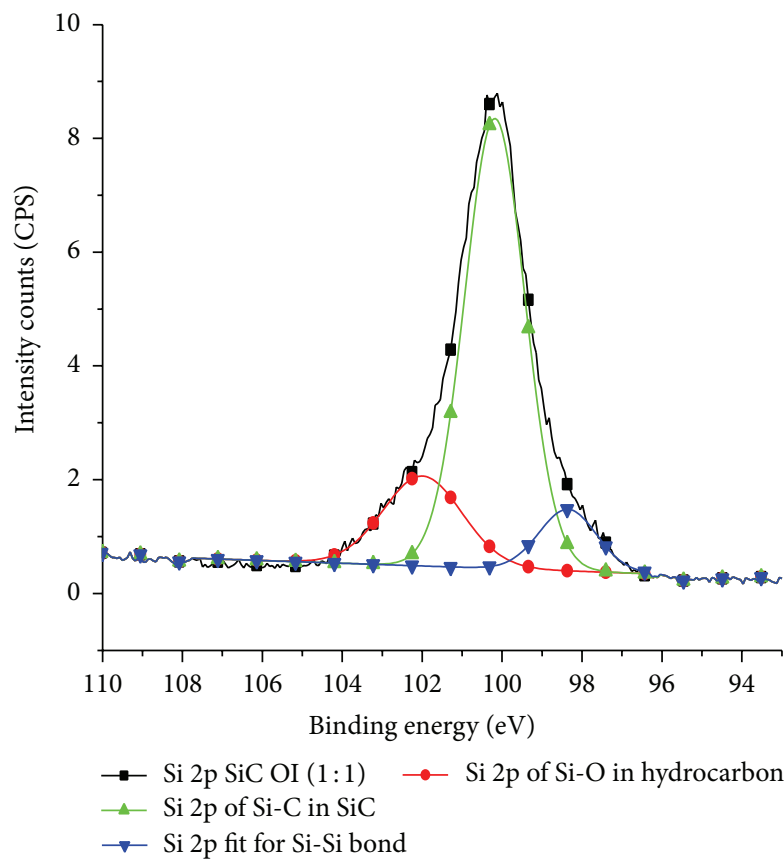

(a) Si $2 p$

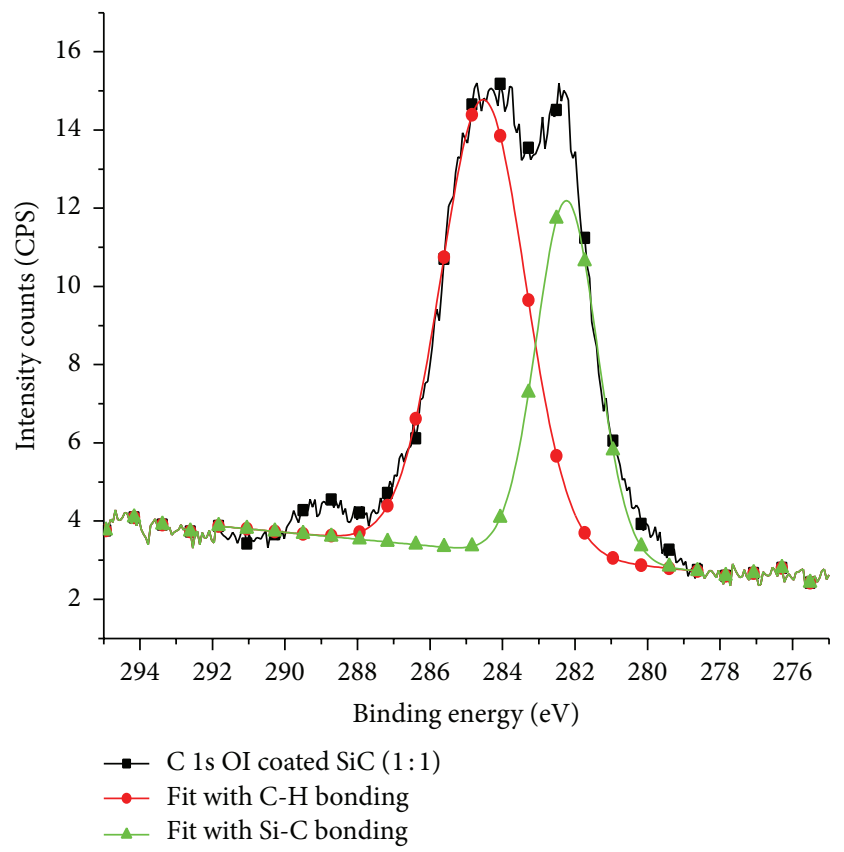

(b) $\mathrm{C} 1 \mathrm{~s}$

FIgURE 4: Deconvoluted XPS spectra for SiC: OI (1:1) peak for (a) Si 2p and (b) C 1s.

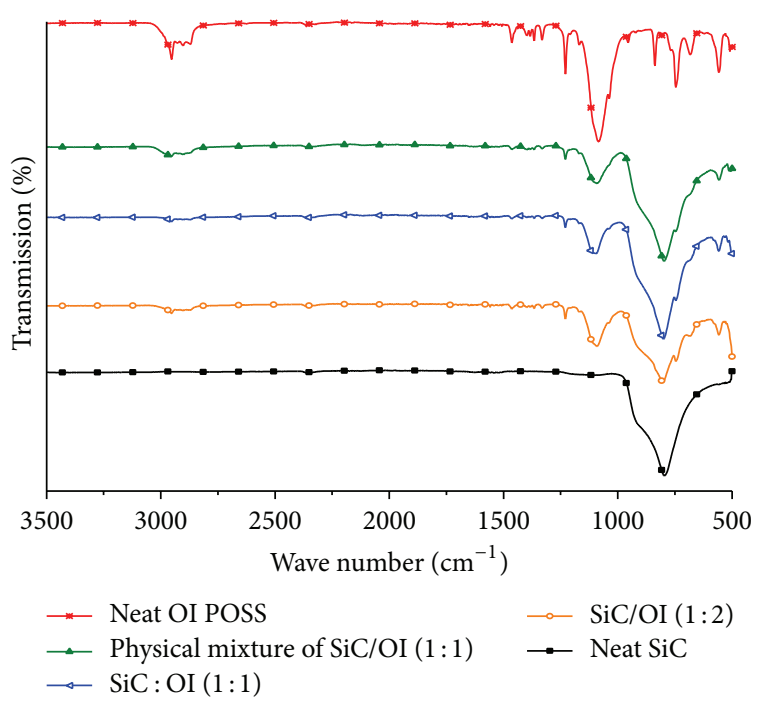

Figure 5: FTIR spectra of SiC and POSS OI coated SiC.

ratio, this $\mathrm{C}-\mathrm{H}_{n}$ bond density diminishes. In a nutshell, the FTIR spectra suggest the $\mathrm{C}-\mathrm{H}_{n}$ group significantly observed in neat OI-POSS, physical mixture of $\mathrm{SiC}$ and OI-POSS, and sonochemical mixture of SiC/OI-POSS (at $1: 2$ ratio). Interestingly, decrease in $\mathrm{C}-\mathrm{H}$ bond density (at wave number $2902 \mathrm{~cm}^{-1}$ ) for $1: 1$ sonochemical mixing of SiC/OI-POSS clearly implies domination of covalent bonding between $\mathrm{SiC}$ and OI-POSS. For sonochemically coated OI-POSS on $\mathrm{SiC}$ at $1: 2$ ratio, most of the peaks match neat OI-POSS indicating the presence of OI-POSS in excess amount. The strong peak observed at $795.3 \mathrm{~cm}^{-1}$ for neat $\mathrm{SiC}$ was also shifted to $801.3 \mathrm{~cm}^{-1}$ in case of sonochemically coated OI-POSS on $\mathrm{SiC}$ $(1: 1)$. This value which is much higher and broader band than any other combination of SiC/OI-POSS further confirms the coating of OI-POSS on $\mathrm{SiC}$ using sonochemical synthesis technique.

3.1.4. Transmission Electron Microscope (TEM). Figure 6 shows representative TEM micrographs of sonochemically coated OI-POSS on $\mathrm{SiC}$ at 1:1 ratio at two different resolutions. Figure 6(a) shows low resolution image of the ascoated OI-POSS on SiC. The high resolution micrographs (Figure 6(b)) clearly revealed the OI-POSS on the surface of $\mathrm{SiC}$ nanoparticles. The despacing of $\mathrm{SiC}(111)(\sim 0.256 \mathrm{~nm})$ and also the despacing of $100 \%$ peak of OI-POSS $(1.11 \mathrm{nmn})$ are shown in Figure 6(b). Because of the larger value of despacing of OI-POSS the SiC particles despacing is not visible in the micrograph provided. These results which are consistent with the XRD, XPS, and FTIR results suggest the coating of OI-POSS on SiC nanoparticles. The micrographs shown in Figure 6 clearly show the uniform coating of OI-POSS on SiC nanoparticles. It was further confirmed that this attachment is not due to physical adsorption or van der Waals interaction but rather due to the covalent bonding between $\mathrm{SiC}$ and OIPOSS as shown from the XPS and FTIR results.

\subsection{Characterization of OI-POSS Coated SiC Epoxy Nanocomposites}

3.2.1. Differential Scanning Calorimetry (DSC). Differential scanning calorimetric experiments were performed in order 


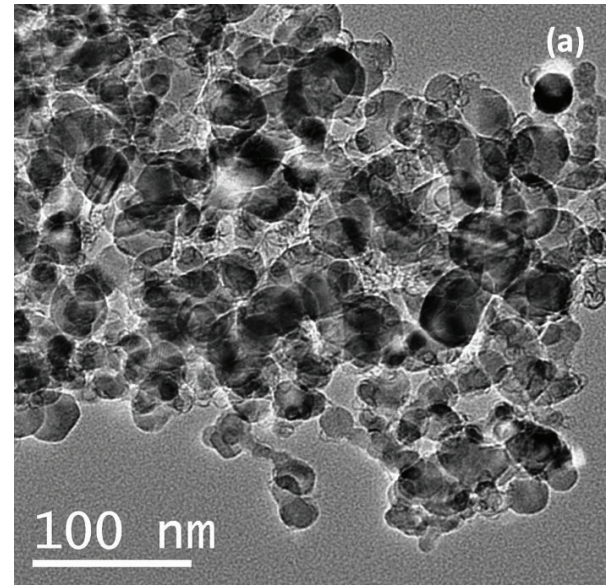

(a)

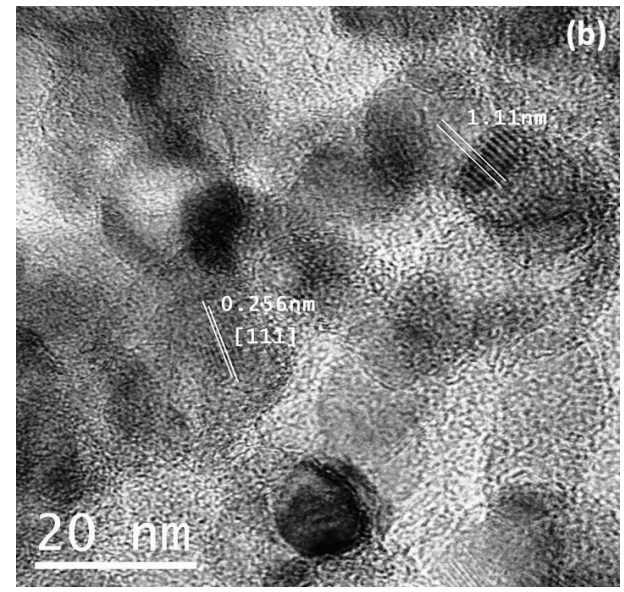

(b)

FIgURE 6: TEM images of (a) OI-POSS coated $\mathrm{SiC}$ and (b) OI-POSS coated $\mathrm{SiC}$ at higher magnification.

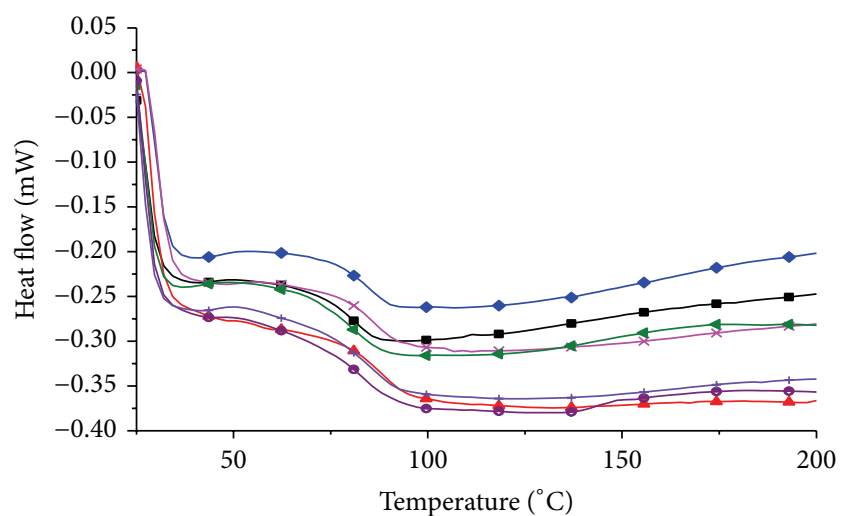

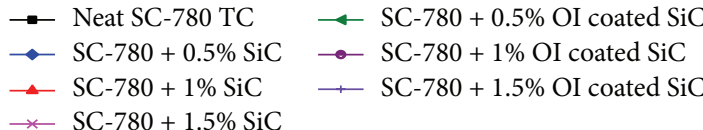

FIGURE 7: DSC graphs of thermally cured SC-780 epoxy resin with different loading of $\mathrm{SiC}$ and POSS OI coated $\mathrm{SiC}$.

to study the glass transition temperature behavior of the nanocomposites compared with neat epoxy. The DSC plots obtained from experimental results of epoxy resin with different percentage of loadings are given in Figure 7 and the results are summarized in Table 3 . These curves represent the room temperature cured SC-780 epoxy resin at different percentages of $\mathrm{SiC}$ nanoparticles and OI-POSS coated $\mathrm{SiC}$ nanoparticles. These graphs show that, with the addition of $\mathrm{SiC}$ nanoparticles, the change in the base line shifted towards the higher temperature as compared with the neat SC-780 epoxy resin system. This indicates the increase of $T_{g}$ for SiC infused SC-780 epoxy resin system. The $T_{g}$ measure from $1 \%$ and $1.5 \%$ loading of $\mathrm{SiC}$ in epoxy cured at room temperature was $88^{\circ} \mathrm{C}$ and $87^{\circ} \mathrm{C}$, respectively. These values are higher than that of $T_{g}$ for neat system $\left(81^{\circ} \mathrm{C}\right)$ as shown in Table 3. It is well established that $T_{g}$ increased with the increasing cross-linking density and decreasing
TABLE 3: Glass transition temperatures of neat SC-780 and OI-POSS coated $\mathrm{SiC}$ nanoparticles infused epoxy nanocomposites.

\begin{tabular}{lc}
\hline Sample name & $\begin{array}{c}T_{g}\left({ }^{\circ} \mathrm{C}\right) \\
\text { Cured at RT }\end{array}$ \\
\hline Neat SC-780 & 81 \\
SC-780 + 0.5\% SiC & 84 \\
SC-780 + 1\% SiC & 88 \\
SC-780 + 1.5\% SiC & 87 \\
SC-780 + 0.5\% OI-POSS coated SiC & 80 \\
SC-780 + 1\% OI-POSS coated SiC & 83 \\
SC-780 + 1.5\% OI-POSS coated SiC & 86 \\
\hline
\end{tabular}

molecular mobility. This is because nanoparticles fill the interpenetration layer of free chains within the cross-link and in other words increase cross-linking density [5, 42]. The addition of SiC nanoparticles up to an optimum level imparts such contribution causing enhancement in $T_{g}$. We have also observed the $T_{g}$ deviation from linear trend for SC-780 $+1 \%$ SiC and SC-780 + 1.5\% SiC samples. Increasing concentrations, the surplus free nanoparticles in the matrix were excluded from the cross-linking chain which resulted in a decreased $T_{g}$. For OI-POSS coated $\mathrm{SiC}$, at lower loading level, the enhancement in $T_{g}$ was not significant because at this level the interaction between $\mathrm{SiC}$ and OI-POSS was more rather than the particles with polymer. However, with higher (1.5\%) concentration of OI-POSS coated $\mathrm{SiC} T_{g}$ increased $\left(86^{\circ} \mathrm{C}\right)$. This increment might be due to the contribution of $\mathrm{SiC}$ in the coated nanoparticles. This phenomenon to some extent suggests that the OI-POSS is acting as a plasticizer rather than the filler in this epoxy resin system. A thorough literature review also suggests that OI-POSS system is more compatible with thermoplastic polymers $[18,19,43,44]$.

3.2.2. Thermogravimetric Analysis (TGA). TGA experiments were performed in order to investigate the thermal stability of neat epoxy and nanoparticles infused nanocomposites. 
TABle 4: Decomposition temperature and residue of neat SC-780 and OI-POSS coated SiC infused SC-780 epoxy nanocomposites.

\begin{tabular}{lcc}
\hline Sample & \multicolumn{2}{c}{ Cured at $25^{\circ} \mathrm{C}$} \\
& $\begin{array}{c}\text { Decomposition } \\
\text { temp. }\left({ }^{\circ} \mathrm{C}\right)\end{array}$ & Residue (\%) \\
\hline Neat SC-780 & 350.82 & 1.19 \\
SC-780 + 0.5\% SiC & 354.87 & 8.95 \\
SC-780 + 1\% SiC & 348.96 & 12.51 \\
SC-780 + 1.5\% SiC & 351.21 & 15.43 \\
SC-780 + 0.5\% OI-POSS coated SiC & 348.96 & 18.14 \\
SC-780 + 1\% OI-POSS coated SiC & 351.12 & 13.95 \\
SC-780 + 1.5\% OI-POSS coated SiC & 353.32 & 14.90 \\
\hline
\end{tabular}

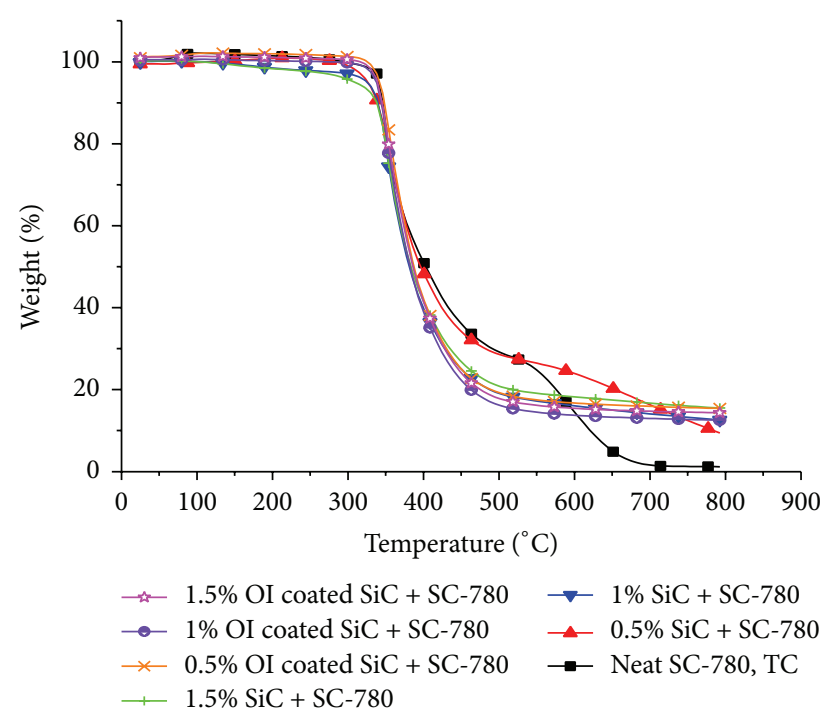

FIGURE 8: TGA graphs of thermally cured SC-780 epoxy with different loading of $\mathrm{SiC}$ and POSS OI coated $\mathrm{SiC}$.

Figure 8 depicts the TGA graph of room temperature cured neat SC-780 epoxy resin system and nanocomposites infused with $\mathrm{SiC}$ and OI-POSS coated SiC. These results are also summarized in Table 4. The TGA results indicate that there is no significant difference in decomposition temperature even after addition of various percentages of $\mathrm{SiC}$ or OIPOSS coated SiC nanoparticles. This also indicates that the nanoparticles are well dispersed and were not acting as impurities in the form of agglomerations. The only significant difference is that the neat epoxy system shows the twostage decomposition. The first one at lower temperature is due to degradation and the second one at high temperature is corresponding to higher cross-linked polymers after heat absorption. Conversely nanocomposites show single-stage decomposition and also the residue is much higher than the neat epoxy system. This clearly shows that, by the addition of nanoparticles, the second step of degradation disappeared because of the uniform heating and produces a higher carbon content as residue.

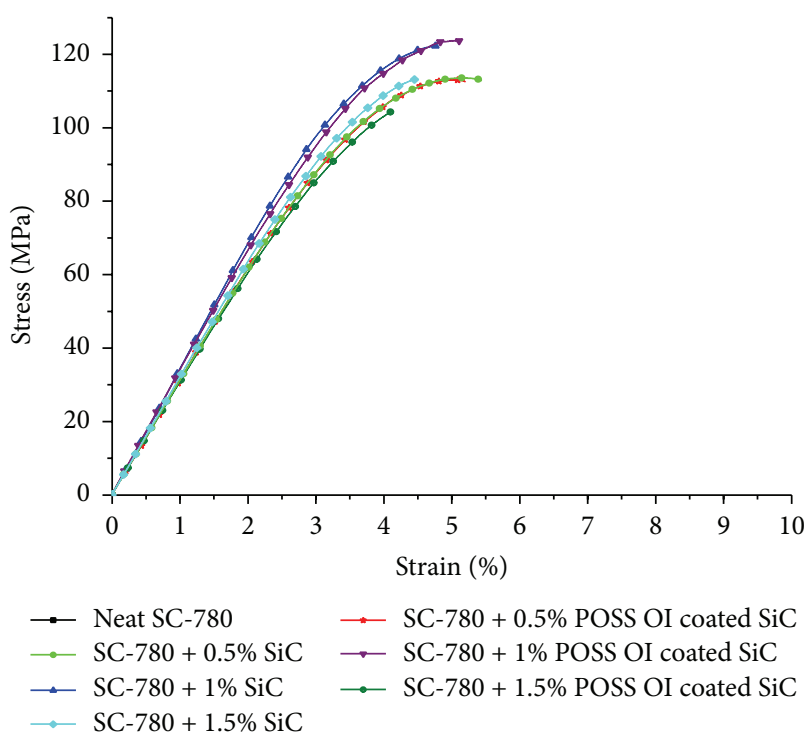

FIGURE 9: Stress-strain curve from flexure results of nanocomposites with $\mathrm{SiC}$ and POSS OI coated SiC.

3.2.3. Flexural Tests. The flexural tests were performed to evaluate the strength and stiffness response of neat epoxy and nanocomposites system. Figure 9 shows the flexural stress strain graph of cured SC-780 epoxy resin system at different loading percentages of $\mathrm{SiC}$ nanoparticles and $\mathrm{OI}-$ POSS coated SiC nanoparticles. These results are also summarized in Table 5. From the graph, it is clear that, with the addition of nanoparticles, the flexural strength and modulus of nanocomposites increased when compared with the neat epoxy matrix. This may be because of the nanoparticles interaction with polymer which restricts the mobility of the polymer chains resulting in better mechanical properties with an optimum level of nanofillers addition. Literature survey clearly shows that higher loading of nanoparticles to matrix system causes the nanocomposites to behave like brittle materials instead of ductile one $[2,3,5]$. The $1 \% \mathrm{SiC}$ nanoparticles infused in the epoxy possess flexural strength and modulus of 120.6 MPa and 3.25 GPa, respectively. The $10-12 \%$ increment in flexural strength and modulus of nanoparticle induced matrix over neat system indicate the energy consumption mechanism by $\mathrm{SiC}$ nanoparticles and further impede and/or delay the specimen failure by flexure. However, the flexural strength and modulus of $1 \%$ OI-POSS coated SiC infused epoxy are $123.1 \mathrm{MPa}$ and $3.34 \mathrm{GPa}$, respectively.

It should be noted here that the OI-POSS coated SiC contain $50 / 50$ of $\mathrm{SiC}$ and OI-POSS and by reducing the amount of $\mathrm{SiC}$ by $50 \%$ in nanocomposites still it is possible to improve the mechanical properties. Moreover, the reason of this better flexural response is that the modification of surface of $\mathrm{SiC}$ by OI-POSS improves the interfacial bonding between nanofillers and surrounding matrix with good dispersion. These interfacial adhesions or bonding enables an effective stress transfer between polymer and nanoparticles which restrict the mobility of polymer chain under loading. It is also interesting to note here an exceptional case, where improvement in maximum strain at failure was observed for 
TABLE 5: Flexure response of neat and nanofilled SC-780 epoxy cured at $25^{\circ} \mathrm{C}$ with postcuring.

\begin{tabular}{|c|c|c|c|c|c|c|}
\hline Sample ID & $\begin{array}{c}\text { Ultimate } \\
\text { flexural strength } \\
(\mathrm{MPa})\end{array}$ & $\begin{array}{c}\text { Gain/loss } \\
\text { in strength } \\
(\%)\end{array}$ & $\begin{array}{l}\text { Average flexural } \\
\text { modulus (GPa) }\end{array}$ & $\begin{array}{c}\text { Gain/loss in } \\
\text { modulus } \\
(\%)\end{array}$ & $\begin{array}{c}\text { Average } \\
\% \\
\text { strain at } \\
\text { maximum force }\end{array}$ & $\begin{array}{l}\text { Gain/loss in } \\
\text { strain }(\%)\end{array}$ \\
\hline Neat SC-780 & $107.7 \pm 2.9$ & - & $2.97 \pm 0.11$ & - & $4.68 \pm 0.35$ & - \\
\hline $\mathrm{SC}-780+0.5 \% \mathrm{SiC}$ & $113.8 \pm 1.2$ & 5.66 & $2.965 \pm 0.02$ & -0.10 & $5.1 \pm 0.57$ & 8.97 \\
\hline $\mathrm{SC}-780+1 \% \mathrm{SiC}$ & $120.6 \pm 3.2$ & 11.98 & $3.25 \pm 0.21$ & 9.43 & $4.96 \pm 0.29$ & 5.98 \\
\hline $\mathrm{SC}-780+1.5 \% \mathrm{SiC}$ & $115.2 \pm 1$ & 6.96 & $3.07 \pm 0.09$ & 3.37 & $5.3 \pm 0.07$ & 13.24 \\
\hline $\begin{array}{l}\text { SC- } 780+0.5 \% \text { POSS } \\
\text { OI coated } \mathrm{SiC}\end{array}$ & $113.1 \pm 1.9$ & 5.01 & $3.02 \pm 0.1$ & 1.68 & $5.07 \pm 0.23$ & 8.33 \\
\hline $\begin{array}{l}\text { SC- } 780+1 \% \text { POSS OI } \\
\text { coated } \mathrm{SiC}\end{array}$ & $123.1 \pm 2.8$ & 14.30 & $3.34 \pm 0.09$ & 12.46 & $4.97 \pm 0.3$ & 6.2 \\
\hline $\begin{array}{l}\text { SC- } 780+1.5 \% \text { POSS } \\
\text { OI coated } \mathrm{SiC}\end{array}$ & $103.3 \pm 3.7$ & -4.09 & $3.04 \pm 0.18$ & 2.36 & $4.10 \pm 0.19$ & -12.4 \\
\hline
\end{tabular}

nanocomposites with $1.5 \%$ loading of $\mathrm{SiC}$. This phenomenon is contrary to conventionally nanofilled composites indicating the better dispersion and exfoliation of nanofillers into nanocomposites. It is believed that the rigid nature of fillers is minimized here for the deformation of polymers. Values obtained from flexural response are shown in Table 3 of the epoxy nanocomposites infused with $\mathrm{SiC}$ and OI-POSS coated $\mathrm{SiC}$ cured at room temperature with 6 hours of postcuring.

3.2.4. Scanning Electron Microscope. The SEM micrographs show the morphology of the fracture surfaces along the failure plane from the flexural response. The micrographs of fracture surface from flexural tests are shown in Figures 10(a)-10(f) for neat SC-780 epoxy resin system and SC780 with $1 \% \mathrm{SiC}$ and with $1 \%$ OI-POSS coated SiC. These micrographs represent the fracture surface of the flexural tested specimens. The top surface of the specimen is under compression and the bottom is under tension. For the neat system it is evident that initial crack formed at the edge of the tension side of the specimen. Relatively smooth surface was observed for neat epoxy system of room temperature cured samples as shown in Figures 10(a) and 10(b) indicating lower interfacial adhesion. Figures 10 (c) and 10(d) illustrate the fracture surface of nanocomposites with $1 \%$ loading of $\mathrm{SiC}$. It was observed that the crack form in the radial direction from a center point at tension side of specimen and relatively rougher surface is seen upon adding $1 \% \mathrm{SiC}$ into epoxy shown in micrographs (Figures 10(c) and 10(d)). These surfaces roughness implies that the propagation of crack tip is distorted because of having $\mathrm{SiC}$ nanoparticles which were intercalated into epoxy causing resistance to crack propagation. As shown in Figures 10(e) and 10(f) the degree of the roughness of fracture surface was observed for nanocomposites infused with OI-POSS coated $\mathrm{SiC}$ nanocomposites. This indicates that the interfacial bonding strength between the nanoparticles and matrix was strong enough to oppose the crack propagation of the nanocomposites and the dispersion of coated nanoparticles was uniform throughout the nanocomposites.

\section{Conclusions}

The $\beta$-SiC nanoparticles were coated with OctaIsobutyl (OI) POSS using the sonochemical synthesis technique. The XRD spectra reveal the existence of both particles in the coated system indicating sharp peaks with crystalline structure of $\mathrm{SiC}$, OI-POSS, and OI-POSS coated $\mathrm{SiC}$ nanoparticles. Moreover, the chemical composition and binding energy of the elements in a depth of $2-10 \mathrm{~nm}$ range of the surface of coated nanomaterial obtained from XPS spectra analyses specify the covalent bonding of OI-POSS SiC nanoparticles. FTIR spectral analyses further confirm the existence of OIPOSS coated onto SiC nanoparticles. The mixing ratio for the sonochemically coated was optimized at $1: 1$ for each OIPOSS system. TEM micrographs also confirm the presence of OI-POSS coating on SiC nanoparticles. The effect of this OI-POSS coated $\mathrm{SiC}$ into thermoset polymer was investigated and it was observed that both $\mathrm{SiC}$ and OI-POSS coated $\mathrm{SiC}$ nanoparticles' infusion into the polymer matrix had a positive effect on thermal and mechanical properties up to an optimum loading level. It was also noticeable that, with $1 \%$ loading of $\mathrm{SiC}$ and OI-POSS coated $\mathrm{SiC}$ in the nanocomposites, the flexural strength was increased by $12 \%$ and $14.3 \%$ over the neat epoxy and the flexural modulus was increased by $9.5 \%$ and $12.5 \%$, respectively, with a minute enhancement in maximum strain to failure. It should be noted here that, with reducing the amount of $\mathrm{SiC}$ by $50 \%$ in coated nanoparticles, still it is possible to enhance the mechanical and thermal properties. The decomposition temperature for neat epoxy and nanocomposites with both untreated and POSS treated $\mathrm{SiC}$ was same. The increments in glass transition temperature for $\mathrm{SiC}$ infused nanocomposites were observed. However, nanocomposites with POSS treated $\mathrm{SiC}$ did not show appreciable increment with respect to untreated $\mathrm{SiC}$ based nanocomposites although there was an improvement in $T_{g}$ with respect to neat epoxy system.

\section{Conflict of Interests}

There is no conflict of interests in this research work. 


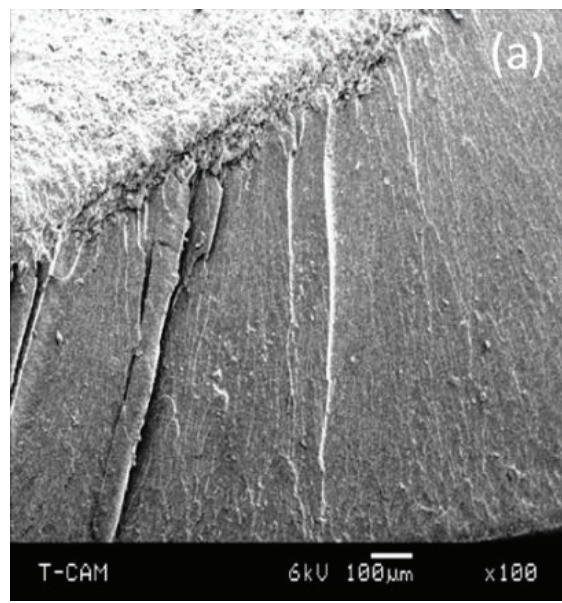

(a)

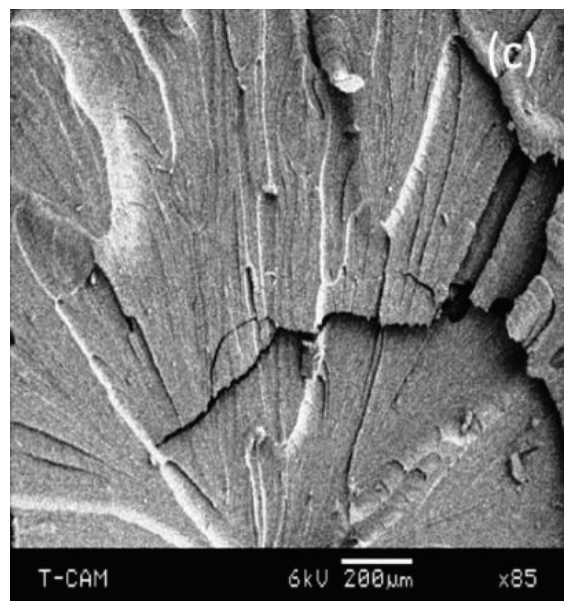

(c)

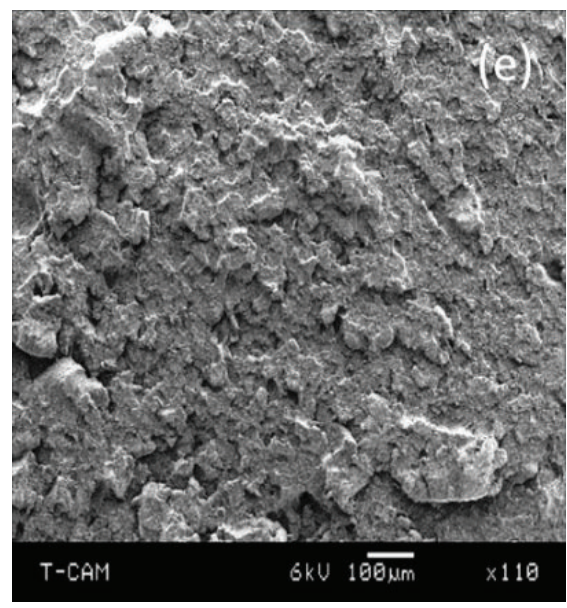

(e)

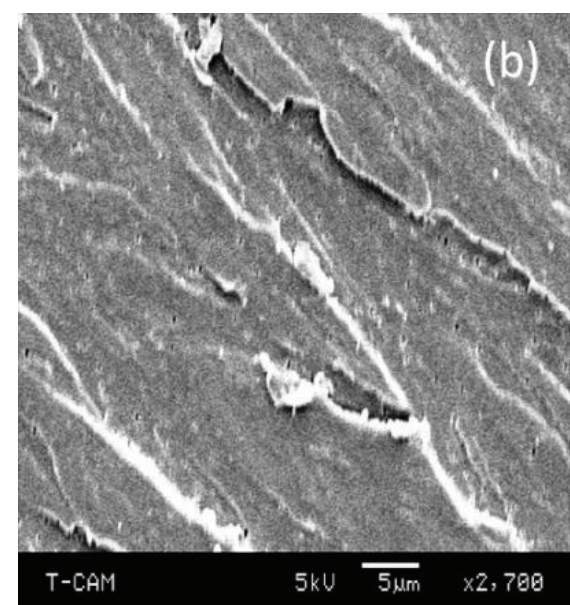

(b)

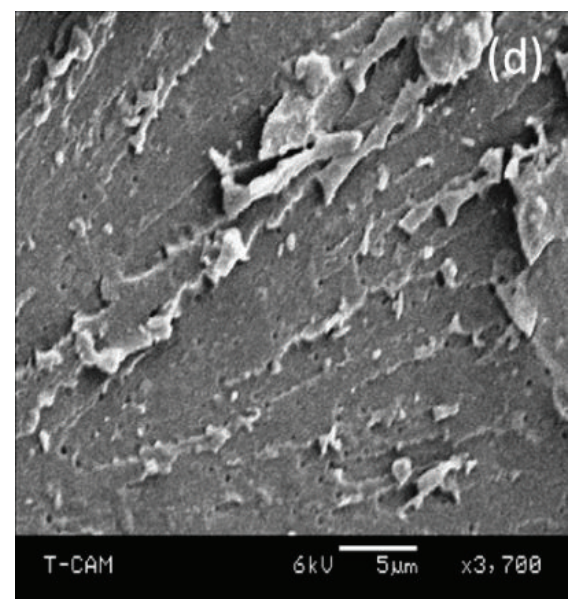

(d)

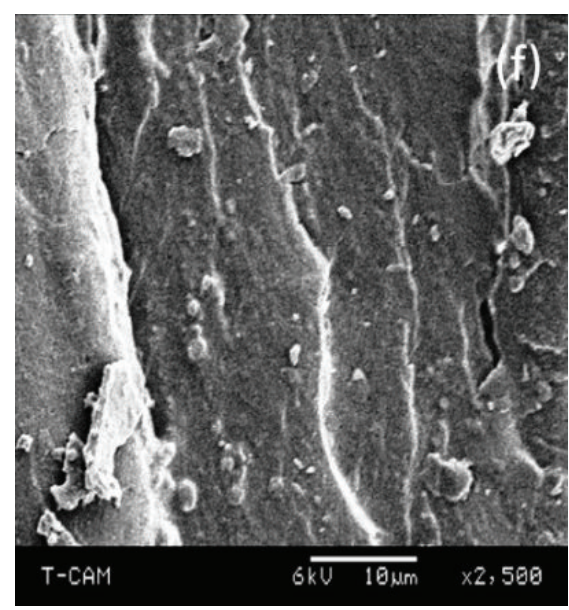

(f)

Figure 10: SEM micrographs of fractured surfaces of nanocomposites for neat SC-780 ((a) and (b)), 1\% SiC loading ((c) and (d)), and 1\% POSS OI coated SiC weight fraction. 


\section{Acknowledgments}

The authors would like to acknowledge NSF-PREM (DMR no. 0611612) and NSF-RISE (HRD no. 0833158) for financial support of this research work. The authors would also like to thank Professor Melissa A. Hines for allowing the authors to use XPS facility at Cornell University. The authors greatly appreciate Dr. Jonathan Shu, Shared Facility Manager at Center for Nanoscale Systems, Cornell University, for his technical assistance in XPS analysis.

\section{References}

[1] S. Bellucci, I. Sacco, F. Micciulla et al., "Preliminary studies on nanocomposite based on high quality Silicon Carbide nanofibers," in Proceedings of the 35th International Semiconductor Conference (CAS '12), pp. 95-98, IEEE, Sinaia, Romania, October 2012.

[2] N. Chisholm, H. Mahfuz, V. K. Rangari, A. Ashfaq, and S. Jeelani, "Fabrication and mechanical characterization of carbon/SiC-epoxy nanocomposites," Composite Structures, vol. 67, no. 1, pp. 115-124, 2005.

[3] Z. Guo, T. Y. Kim, K. Lei, T. Pereira, J. G. Sugar, and H. T. Hahn, "Strengthening and thermal stabilization of polyurethane nanocomposites with silicon carbide nanoparticles by a surfaceinitiated-polymerization approach," Composites Science and Technology, vol. 68, no. 1, pp. 164-170, 2008.

[4] A. Nassar and E. Nassar, "Study on mechanical properties of epoxy polymer reinforced with NanoSiC particles," Journal of NanoScience, NanoEngineering \& Applications, vol. 1, no. 2, pp. 89-93, 2013.

[5] R. M. Rodgers, H. Mahfuz, V. K. Rangari, N. Chisholm, and $\mathrm{S}$. Jeelani, "Infusion of $\mathrm{SiC}$ nanoparticles into SC-15 epoxy: an investigation of thermal and mechanical response," Macromolecular Materials and Engineering, vol. 290, no. 5, pp. 423429, 2005.

[6] J. A. Costello and R. E. Tressler, "Oxidation kinetics of silicon carbide crystals and ceramics: I, in dry oxygen," Journal of the American Ceramic Society, vol. 69, no. 9, pp. 674-681, 1986.

[7] C. Önneby and C. G. Pantano, "Silicon oxycarbide formation on $\mathrm{SiC}$ surfaces and at the $\mathrm{SiC} / \mathrm{SiO}_{2}$ interface," Journal of Vacuum Science and Technology A: Vacuum, Surfaces and Films, vol. 15, no. 3, pp. 1597-1602, 1997.

[8] M. Sarret, C. Müller, and A. Amell, "Characterization of SiC and $\mathrm{Si}_{3} \mathrm{~N}_{4}$ nanoparticles and their aqueous dispersions," Journal of Nanoparticle Research, vol. 9, no. 6, pp. 1073-1080, 2007.

[9] T. Shimoo, K. Okamura, and Y. Morisada, "Active-to-passive oxidation transition for polycarbosilane-derived silicon carbide fibers heated in $\mathrm{Ar}-\mathrm{O}_{2}$ gas mixtures," Journal of Materials Science, vol. 37, no. 9, pp. 1793-1800, 2002.

[10] R. P. Socha, K. Laajalehto, and P. Nowak, "Influence of the surface properties of silicon carbide on the process of $\mathrm{SiC}$ particles codeposition with nickel," Colloids and Surfaces A: Physicochemical and Engineering Aspects, vol. 208, no. 1-3, pp. 267-275, 2002.

[11] J. Che, X. Wang, Y. Xiao, X. Wu, L. Zhou, and W. Yuan, "Effect of inorganic-organic composite coating on the dispersion of silicon carbide nanoparticles in non-aqueous medium," Nanotechnology, vol. 18, no. 13, Article ID 135706, 2007.
[12] W. Gang, Z. Shaofeng, M. Yuedong, and S. Xingsheng, "Surface modification of SiC nanoparticles with PMMA by low temperature plasma," Plasma Science and Technology, vol. 9, no. 1, pp. 57-61, 2007.

[13] M. Iijima and H. Kamiya, "Surface modification of silicon carbide nanoparticles by azo radical initiators," Journal of Physical Chemistry C, vol. 112, no. 31, pp. 11786-11790, 2008.

[14] Y. Zhang and J. Binner, "In situ surface modification of silicon carbide particles using $\mathrm{Al}^{3+}$ complexes and polyelectrolytes in aqueous suspensions," Journal of the American Ceramic Society, vol. 85, no. 3, pp. 529-534, 2002.

[15] E. Ayandele, B. Sarkar, and P. Alexandridis, "Polyhedral Oligomeric Silsesquioxane (POSS)-containing polymer nanocomposites," Nanomaterials, vol. 2, no. 4, pp. 445-475, 2012.

[16] J. Boček, L. Matějka, V. Mentlík, P. Trnka, and M. Šlouf, "Electrical and thermomechanical properties of epoxy-POSS nanocomposites," European Polymer Journal, vol. 47, no. 5, pp. 861-872, 2011.

[17] N. T. Dintcheva, E. Morici, R. Arrigo, F. P. La Mantia, V. Malatesta, and J. J. Schwab, "Structure-properties relationships of polyhedral oligomeric silsesquioxane (POSS) filled PS nanocomposites," Express Polymer Letters, vol. 6, no. 7, pp. 561-571, 2012.

[18] A. Fina, H. C. L. Abbenhuis, D. Tabuani, A. Frache, and G. Camino, "Polypropylene metal functionalised POSS nanocomposites: a study by thermogravimetric analysis," Polymer Degradation and Stability, vol. 91, no. 5, pp. 1064-1070, 2006.

[19] A. Fina, D. Tabuani, A. Frache, and G. Camino, "Polypropylenepolyhedral oligomeric silsesquioxanes (POSS) nanocomposites," Polymer, vol. 46, no. 19, pp. 7855-7866, 2005.

[20] H. Ghanbari, A. de Mel, and A. M. Seifalian, "Cardiovascular application of polyhedral oligomeric silsesquioxane nanomaterials: a glimpse into prospective horizons," International Journal of Nanomedicine, vol. 6, pp. 775-786, 2011.

[21] D. Gnanasekaran, K. Madhavpan, and R. S. R. Reddy, "Developments of polyhedral oligomeric silsesquioxanes (POSS), POSS nanocomposites and their applications: a review," Journal of Scientific and Industrial Research, vol. 68, no. 6, pp. 437-464, 2009.

[22] I. K. Jones, Y. X. Zhou, S. Jeelani, and J. M. Mabry, "Effect of polyhedral-oligomeric-sil-sesquioxanes on thermal and mechanical behavior of SC-15 epoxy," Express Polymer Letters, vol. 2, no. 7, pp. 494-501, 2008.

[23] G. Li, L. Wang, H. Ni, and C. U. Pittman Jr., "Polyhedral oligomeric silsesquioxane (POSS) polymers and copolymers: a review," Journal of Inorganic and Organometallic Polymers, vol. 11, no. 3, pp. 123-154, 2001.

[24] L. Matějka, A. Strachota, J. Pleštil, P. Whelan, M. Steinhart, and M. Šlouf, "Epoxy networks reinforced with polyhedral oligomeric silsesquioxanes (POSS). Structure and morphology," Macromolecules, vol. 37, no. 25, pp. 9449-9456, 2004.

[25] A. Miniewicz, J. Girones, P. Karpinski, B. Mossety-Leszczak, H. Galina, and M. Dutkiewicz, "Photochromic and nonlinear optical properties of azo-functionalized POSS nanoparticles dispersed in nematic liquid crystals," Journal of Materials Chemistry C, vol. 2, no. 3, pp. 432-440, 2014.

[26] K. Pielichowski, J. Njuguna, B. Janowski, and J. Pielichowski, "Polyhedral oligomeric silsesquioxanes (POSS)-containing nanohybrid polymers," in Supramolecular Polymers Polymeric Betains Oligomers, vol. 201 of Advances in Polymer Science, pp. 225-296, Springer, Berlin, Germany, 2006. 
[27] H. K. Raut, S. S. Dinachali, A. Y. He et al., "Robust and durable polyhedral oligomeric silsesquioxane-based anti-reflective nanostructures with broadband quasi-omnidirectional properties," Energy and Environmental Science, vol. 6, no. 6, pp. 1929-1937, 2013.

[28] A. Strachota, I. Kroutilová, J. Kovářová, and L. Matějka, “Epoxy networks reinforced with polyhedral oligomeric silsesquioxanes (POSS). Thermomechanical properties," Macromolecules, vol. 37, no. 25, pp. 9457-9464, 2004.

[29] Y. Xue, Y. Liu, F. Lu, J. Qu, H. Chen, and L. Dai, "Functionalization of graphene oxide with polyhedral oligomeric silsesquioxane (POSS) for multifunctional applications," Journal of Physical Chemistry Letters, vol. 3, no. 12, pp. 1607-1612, 2012.

[30] L. Gardella, A. Basso, M. Prato, and O. Monticelli, "PLA/POSS nanofibers: a novel system for the immobilization of metal nanoparticles," ACS Applied Materials and Interfaces, vol. 5, no. 16, pp. 7688-7692, 2013.

[31] S. K. Yadav, S. S. Mahapatra, H. J. Yoo, and J. W. Cho, "Synthesis of multi-walled carbon nanotube/polyhedral oligomeric silsesquioxane nanohybrid by utilizing click chemistry," Nanoscale Research Letters, vol. 6, no. 1, article 122, 2011.

[32] J. Godnjavec, B. Znoj, N. Veronovski, and P. Venturini, "Polyhedral oligomeric silsesquioxanes as titanium dioxide surface modifiers for transparent acrylic UV blocking hybrid coating," Progress in Organic Coatings, vol. 74, no. 4, pp. 654-659, 2012.

[33] H. Mahfuz, F. Powell, R. Granata, M. Hosur, and M. Khan, "Coating of carbon fiber with polyhedral oligomeric silsesquioxane (POSS) to enhance mechanical properties and durability of carbon/vinyl ester composites," Materials, vol. 4, no. 9, pp. 1619-1631, 2011.

[34] B. Song, L. H. Meng, and Y. D. Huang, "Improvement of interfacial property between $\mathrm{PBO}$ fibers and epoxy resin by surface grafting of Polyhedral Oligomeric Silsesquioxanes (POSS)," Applied Surface Science, vol. 258, no. 24, pp. 10154-10159, 2012.

[35] Y. S. Lai, C. W. Tsai, H. W. Yang, G. P. Wang, and K. H. $\mathrm{Wu}$, "Structural and electrochemical properties of polyurethanes/polyhedral oligomeric silsesquioxanes (PU/POSS) hybrid coatings on aluminum alloys," Materials Chemistry and Physics, vol. 117, no. 1, pp. 91-98, 2009.

[36] G. Markevicius, S. Chaudhuri, C. Bajracharya et al., "Polyoligomeric silsesquioxane (POSS)-hydrogenated polybutadiene polyurethane coatings for corrosion inhibition of AA2024," Progress in Organic Coatings, vol. 75, no. 4, pp. 319-327, 2012.

[37] K. Shimoda, J.-S. Park, T. Hinoki, and A. Kohyama, "Influence of surface structure of $\mathrm{SiC}$ nano-sized powder analyzed by $\mathrm{X}$-ray photoelectron spectroscopy on basic powder characteristics," Applied Surface Science, vol. 253, no. 24, pp. 9450-9456, 2007.

[38] Y. Hijikata, H. Yaguchi, M. Yoshikawa, and S. Yoshida, "Composition analysis of $\mathrm{SiO}_{2} / \mathrm{SiC}$ interfaces by electron spectroscopic measurements using slope-shaped oxide films," Applied Surface Science, vol. 184, no. 1-4, pp. 161-166, 2001.

[39] K. Liang, G. Li, H. Toghiani, J. H. Koo, and C. U. Pittman Jr., "Cyanate ester/polyhedral oligomeric silsesquioxane (POSS) nanocomposites: synthesis and characterization," Chemistry of Materials, vol. 18, no. 2, pp. 301-312, 2006.

[40] E. Tegou, V. Bellas, E. Gogolides et al., "Polyhedral oligomeric silsesquioxane (POSS) based resists: material design challenges and lithographic evaluation at $157 \mathrm{~nm}$," Chemistry of Materials, vol. 16, no. 13, pp. 2567-2577, 2004.

[41] J. Zeng, C. Bennett, W. L. Jarrett et al., "Structural changes in trisilanol POSS during nanocomposite melt processing," Composite Interfaces, vol. 11, no. 8-9, pp. 673-685, 2005.
[42] A. Fina, D. Tabuani, F. Carniato, A. Frache, E. Boccaleri, and G. Camino, "Polyhedral Oligomeric Silsesquioxanes (POSS) thermal degradation," Thermochimica Acta, vol. 440, no. 1, pp. 36-42, 2006.

[43] S. Li, G. P. Simon, and J. G. Matisons, "Morphology of blends containing high concentrations of POSS nanoparticles in different polymer matrices," Polymer Engineering and Science, vol. 50, no. 5, pp. 991-999, 2010.

[44] L. Liu, M. Tian, W. Zhang, L. Zhang, and J. E. Mark, "Crystallization and morphology study of polyhedral oligomeric silsesquioxane (POSS)/polysiloxane elastomer composites prepared by melt blending," Polymer, vol. 48, no. 11, pp. 3201-3212, 2007. 

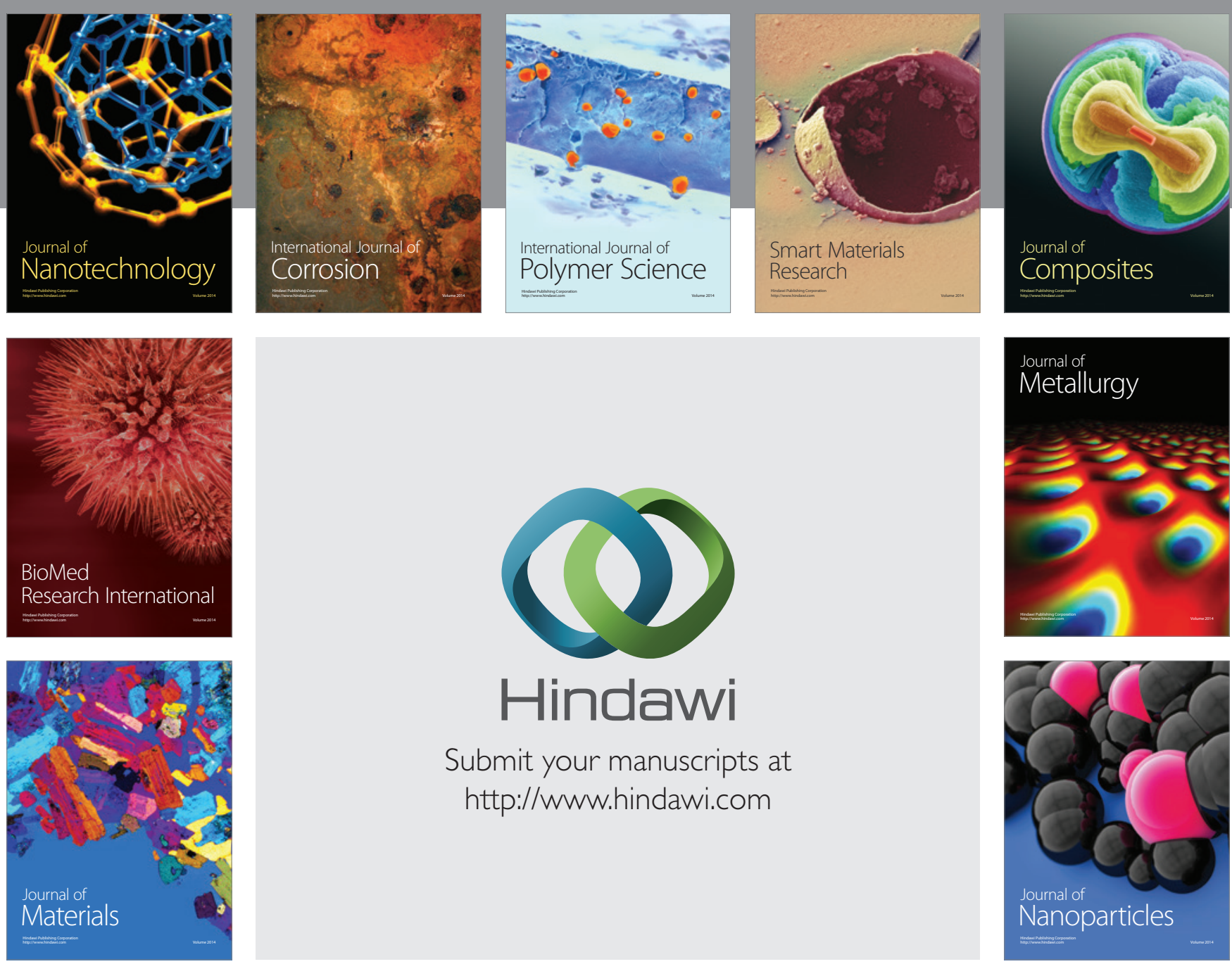

Submit your manuscripts at http://www.hindawi.com
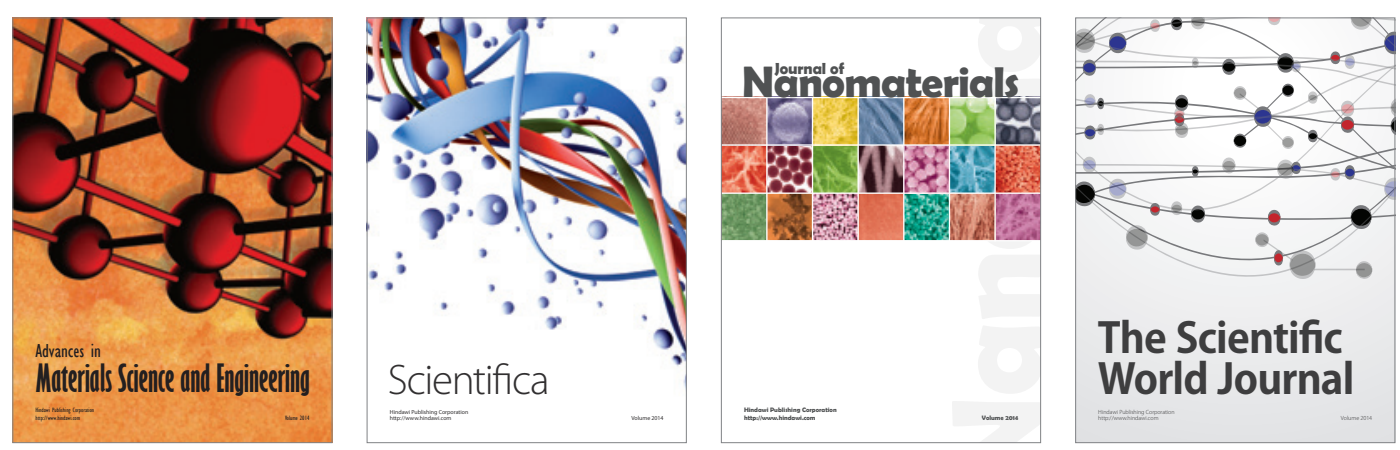

\section{The Scientific World Journal}
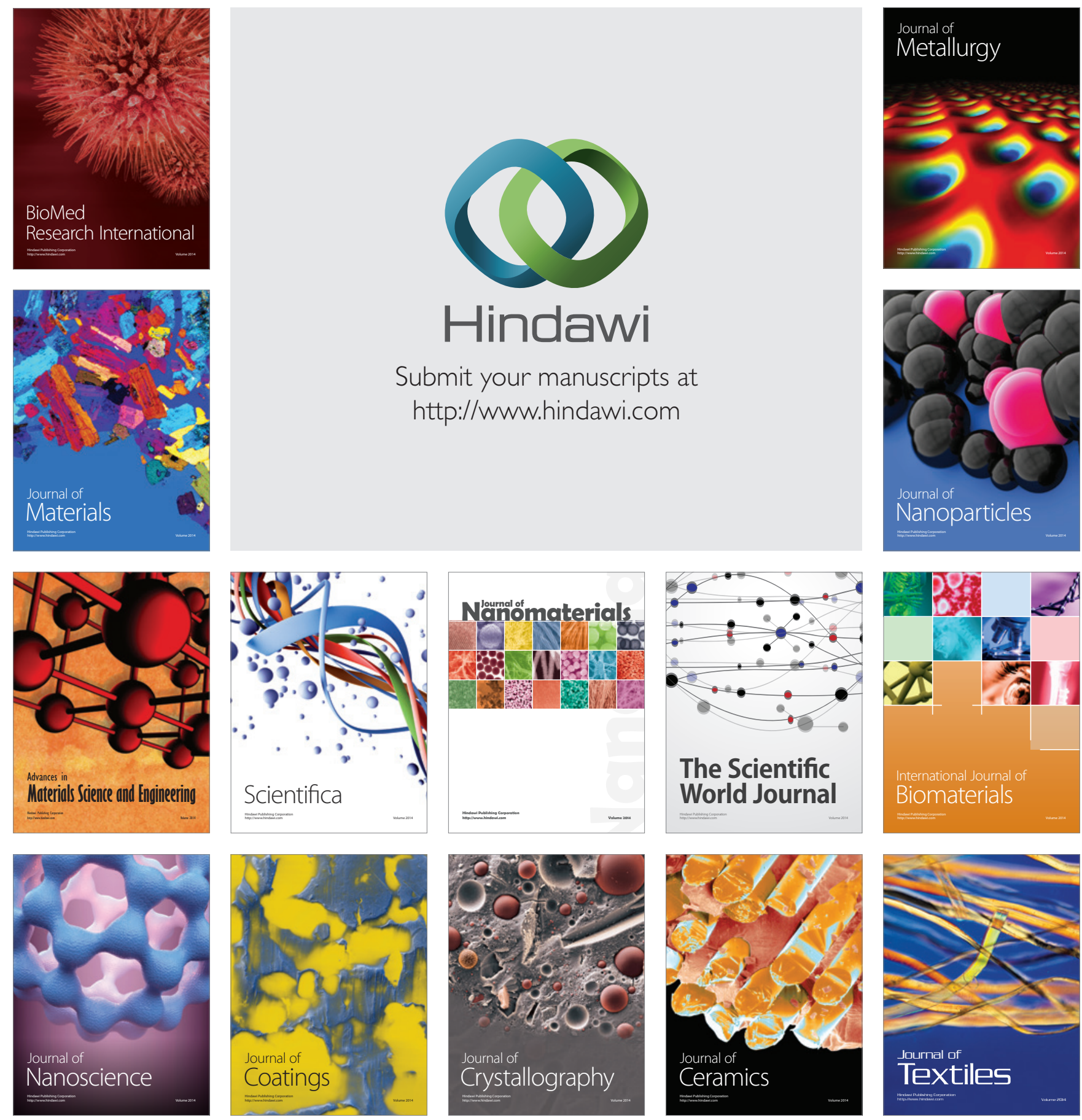